Thus the differences probably reflect the synthesis of RNA during the last $15 \mathrm{~min}$ during which the animals were learning. Zemp et al. reported an increase in the rate of synthesis of RNA in the brains of mice after 15 min of training in a shock avoidance task ${ }^{4}$. The labelled RNA made during this period may be messenger RNA, although other RNA species cannot be excluded.

Our results suggest the synthesis of "unique" species of RNA during learning, a conclusion consistent with those of Hydén and others who have suggested that RNA has a unique role in learning events ${ }^{5}$. This is, however, still a hypothesis awaiting definitive testing. The DNARNA hybridization techniques are difficult and have serious pitfalls ${ }^{3}$, and we were sceptical initially of the results in the previous studies. But, because we have obtained essentially the same results consistently, we think that "unique" RNA species may be present. We are, however, continuing our experiments using further controls and are attempting to determine the physical and chemical characteristics of this RNA.

We thank Drs M. Miyagi, M. Takai and B. C. W. Hummel, and other members of the Molecular Psychobiology Laboratory, for discussions during this research. The research was supported by the US Navy and grants from the National Research Council of Canada.

Barry MaCHLUs
JoHN GAITO
Molecular Psychobiology Laboratory,
York University,
Toronto, Ontario.
Received December 2, 1968; revised January 13, 1969.
' Machlus, B., and Gaito, J., Psychon. Sci., 10, 253 (1968).
' Machlus, B., and Gaito, J., Psychon. Sci., 12, 111 (1968).
3 Gillespie, D., and Spiegelman, S., J. Mol. Biol., 12, 829 (1965).
- Zemp, J. W., Wilson, J. E., Schlesinger, K., Boggan, W. O., and Glassman,
E., Proc. US Nat. Acad. Sci., 55, 1423 (1966).
'Gaito, J., Molecular Psychobiology (C. C. Thornas, Springfield, Ill., 1966).

\section{Heat Resistance and Pigmented Variants of Rhizobium}

Following the work of Löhnis ${ }^{1}$, the occurrence of heatresistant spores in aerobic nitrogen-fixing bacteria has been the subject of some controversy. The chief protagonist in recent years has been Bisset, who claimed that endospores could be demonstrated in Rhizobium from wild leguminous plants ${ }^{2}$ and in strains of tropical origin ${ }^{3}$. Bisset ${ }^{4}$ suggested that Rhizobium and Azotobacter are aberrant sporing bacilli, related to Clostridium, which has several nitrogen-fixing species, and especially to Bacillus polymyxa, which is also capable of fixing nitrogen ${ }^{5}$. Although occasional support has been given to this concept ${ }^{6,7}$, most investigators have found neither spores nor heat resistance in these bacteria. It is notable that, apparently without exception, these studies have been made on strains of Rhizobium from cultivated temperate crop plants, and thereby serve only to confirm Bisset's finding that few of these produce spores.

During genetic studies on Rhizobium meliloti, $R$. leguminosarum and $R$. trifolii, I occasionally observed spore-like bodies in microscopic preparations ${ }^{8}$, although they did not stain with diagnostic spore stains. Cells from cultures containing these spore-like bodies were mildly heat-resistant, being capable of surviving $70^{\circ} \mathrm{C}$, but only exceptionally $80^{\circ} \mathrm{C}$, for $30 \mathrm{~min}$. The proportion of cells surviving heat treatment varied with the compo. sition of the medium and the age of the culture. The last point is important, because, for example, Graham et al. ${ }^{9}$, who found no spores or heat resistance, used 10 day old cultures when looking for spores, and 3 day old cultures when testing for heat resistance.
Further experiments on strains from Rhizobium meliloti cultures that had survived heat-testing confirmed an interesting, but neglected, observation made by Bisset ${ }^{2}$. Orange pigmented variants occurred in these cultures; they were non-infective for the host plant, and often very heat resistant, being capable of surviving $100^{\circ} \mathrm{C}$ for $20 \mathrm{~min}$. Purified strains of the orange pigmented variants, isolated from single colonies, produced reverse mutants when plated on agar. These lost their pigmentation and their extreme heat resistance, but recovered their infectivity. In most cases, these reverse mutations occurred freely and spontaneously, but some pigmented strains were more stable, and reverted only after ultraviolet irradiation. It would seem that orange pigmentation and heat resistance are genetically linked and are inversely related to infectivity.

Similar pigmented variants have been isolated in other laboratories (personal communication from S. Dehlin and D. Hubbell) although in most cases their significance has not been further investigated.

This work was supported by grants from the Swedish National Science and Agricultural Research Councils and the Royal Agricultural College of Sweden.

Department of Microbiology,

\section{B. O. GILlberg}

Royal Agricultural College of Sweden,

Ultuna, Uppsala 7.

Received January 15, 1969.

'Löhnis, F., and Smith, N. R., J. Agric. Res., 28, 401 (1923).

2 Bisset, K. A., J. Gen. Microbiol., 7, 233 (1952).

${ }^{3}$ Bisset, K. A., J. Gen. Microbiol., 20, 89 (1959).

+ Bisset, K. A., Nature, 182, 405 (1958).

${ }^{5}$ Hino, S., and Wilson, P. W., J. Bact., 75, 403 (1958).

- Garbosky, A. J., and Giambiagi, N., Ann. Inst. Pasteur, 105, 202 (1963).

${ }^{7}$ Rubio, M., and Tajerina, G., Microbiol. Espan., 10, 305 (1957).

${ }^{8}$ Gillberg, B. O., Arch. Mikrobiol., 62, 328 (1968).

Graham, P. H., Parker, C. A., Oakley, R. T., Lange, R. T., and Sandersou,

\section{Electron Microscope Study of the Viricidal Properties of Sodium Magnesium-chlorophyllin}

THE therapeutic effect of sodium magnesium-chlorophyllin in patients with herpes simplex and herpes zoster ${ }^{1}$ has aroused our interest in the mechanism of its viricidal activity. In the case of herpetic keratitis, locally applied sodium magnesium-chlorophyllin is as effective as kericid ${ }^{2}$
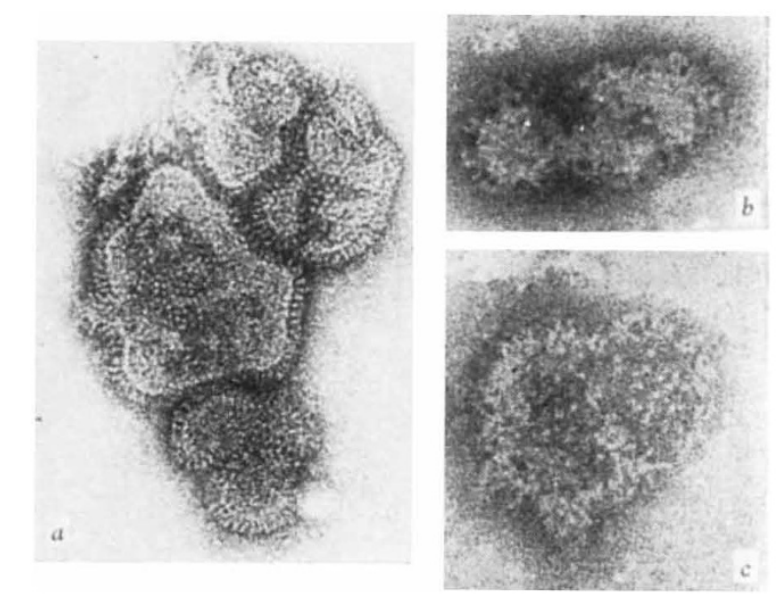

Fig. 1. $a$, Native influenza A2 virus (control) $(\times 120,000) ; b$, influenza A2 virus after interaction for 3 min with sodium magnesium-chlorophyllin solution $(\times 120,000) ; c$, influenza A2 virus after interaction for $30 \mathrm{~min}$
with sodium magnesium-chlorophyllin solution $(\times 120,000)$. 